\title{
Uncovering the Mechanism of the $\mathrm{Ag}(\mathrm{I}) /$ Persulfate-Catalyzed Cross-Coupling Reaction of Arylboronic Acids and Heteroarenes
}

\author{
Niki R. Patel and Robert A. Flowers II \\ Department of Chemistry, Lehigh University, Bethlehem, PA 18015, United States
}

\section{Abstract}

The catalytic cross-coupling of arylboronic acids with pyridines through single electron oxidation provides efficient access to substituted heterocycles. Although important, there is very little known about the mechanism of the reaction and as a consequence, it is unclear if the full scope of the transformation has been realized. In this communication we present kinetic and spectroscopic evidence showing a high degree of complexity in the reaction system. The mechanism derived from these studies shows the activation of $\mathrm{Ag}(\mathrm{I})$ for reduction of persulfate and an off-cycle protodeboronation by pyridine substrate. These results provide key mechanistic insights that enable control of the off-cycle process thus providing higher efficiency and yield.

Catalytic oxidations that proceed through single electron transfer are becoming one of the most important approaches for the formation of $\mathrm{C}-\mathrm{C}$ bonds in molecules of pharmaceutical and biological importance. ${ }^{1} \mathrm{~A}$ great deal of recent effort has focused on two general methods: 1) visible light photoredox catalysis ${ }^{2}$ and 2) metal-catalyzed oxidations. ${ }^{3}$ In both approaches, the use of a terminal oxidant is often required. In addition, the use of readily available starting materials employed in these reactions can provide a wide range of related structures important for screening in medicinal chemistry and for the construction of building blocks important in materials chemistry. In this vein, the recent work of Baran on the $\mathrm{Ag}(\mathrm{I}) /$ persulfate cross-coupling of arylboronic acids with electron deficient pyridines is of fundamental importance. ${ }^{4}$ The approach developed by Baran overcomes several of the shortcomings of the traditional Minisci reaction, ${ }^{5}$ most importantly the addition of aryl radicals to an aromatic heterocycle. In addition, the method is procedurally elegant and has broad substrate scope. Although the reaction provides access to a variety of substituted heteroarenes, a second addition of $\mathrm{Ag}$ catalyst and stoichiometric oxidant are often required. Given the importance of this bond- forming reaction, it is our supposition that a detailed mechanistic study of the system would facilitate a more efficient approach to reaction design using the $\mathrm{Ag}(\mathrm{I}) /$ persulfate catalytic system. Herein, we present mechanistic data defining the role of the individual components in the reaction that reveal a great degree of mechanistic complexity, that once understood provides a more effective approach to this catalytic system, thus extending its utility.

To study the system, the reaction of 4-trifluoromethyl pyridine $(\mathbf{1}, 1 \mathrm{mmol})$ and $p$ tolylboronic acid $\left(\mathbf{2}, 1.5 \mathrm{mmol}\right.$ ) containing $20 \mathrm{~mol} \% \mathrm{AgNO}_{3}$ (with respect to $\mathbf{1}$ ), potassium persulfate $(3 \mathrm{mmol})$ and trifluoroacetic acid (TFA, $1 \mathrm{mmol})$ in a 1:1 solution of dichloromethane (DCM) and water was examined. Protonation of pyridine by TFA produces a better radicophile and enhances selectivity of the 2-position. ${ }^{6}$ To maintain controlled reaction conditions, solvents were degassed and the reaction was carried out under an

Corresponding Author: rof2@ lehigh.edu.

Supporting Information

Experimental procedures, kinetic data, and spectral data. This material is available free of charge via the Internet at http://pubs.acs.org 
atmosphere of argon as shown in Scheme 1. The exclusion of air from the reaction resulted in a $76 \%$ isolated yield, compared to the $81 \%$ yield reported by Baran and coworkers, which required a second addition of $\mathrm{K}_{2} \mathrm{~S}_{2} \mathrm{O}_{8}$ and $\mathrm{AgNO}_{3} \cdot{ }^{4}$

Additionally, toluene was obtained as a side product in roughly $30 \%$ yield (with respect to 2). Removal of oxygen and the subsequent increased yield is consistent with the previously proposed free-radical mechanism. ${ }^{4}$ These higher-yielding conditions were suitable for thorough mechanistic studies.

Kinetic studies were performed in which either the loss of starting material (1) or growth of product was followed over time via gas chromatography (GC). A "same excess" experiment was initiated to determine the stability of catalytic silver nitrate during the course of the reaction ${ }^{7}$ using the conditions contained in Table 1 . If total catalyst concentration remains constant during the course of the reaction, the rates of both reactions would be identical. When rate profiles of Runs 1 and 2 are compared, the decays do not overlay, consistent with a decrease in $\left[\mathrm{AgNO}_{3}\right]$ during the course of the reaction (Figure 1).

To determine the rate orders of each of the substrates in the reaction "different excess" experiments were performed. The reaction was approximately first order in $\mathbf{1}$ and $\mathrm{AgNO}_{3}$. Initial experiments showed that the rate order of $\mathrm{K}_{2} \mathrm{~S}_{2} \mathrm{O}_{8}$ was zero. Given the low solubility of $\mathrm{K}_{2} \mathrm{~S}_{2} \mathrm{O}_{8}$ it is possible that its true rate order could be masked by phase transfer. To examine this physical process, the more soluble $\mathrm{Na}_{2} \mathrm{~S}_{2} \mathrm{O}_{8}$ was employed in the reaction and a rate order of approximately 1 was observed. Surprisingly, an increase in the initial concentration of $\mathbf{2}$ resulted in an overall decrease in reaction rate (Figure 2). The order of $\mathbf{2}$ was determined through normalization of $-\mathrm{d}[1] / \mathrm{dt}$, defined by eq 1

$$
-\frac{\frac{d[1]}{d t}}{[2]^{x}}=k_{o b s}[\mathbf{1}]
$$

where $\mathrm{x}$ is the order of $\mathbf{2}$. Overlay of the two reaction profiles is observed when $\mathrm{x}=-0.5$, indicative of an inverse half order for $\mathbf{2}$ (Figure 2, inset).

The rate orders for all reaction components are shown in Table 2. The rate orders of persulfate and $\mathrm{AgNO}_{3}$ are consistent with a process where catalytic $\mathrm{Ag}(\mathrm{I})$ is oxidized by persulfate. The orders obtained for $\mathbf{1}$ and $\mathbf{2}$ are surprising. If the reaction is indeed proceeding through initial oxidation of $\mathbf{2}$ followed by addition to $\mathbf{1}$, the first order observed for $\mathbf{1}$ compared to the inverse half order for $\mathbf{2}$ suggests a more complicated process.

The formation of silver-pyridine complexes is well- established in the literature. ${ }^{8}$ In addition, there is literature precedence describing the activation of $\mathrm{Ag}(\mathrm{I})$ by amines toward oxidation by persulfate. ${ }^{9}$ Bonchev and Aleksiev showed that the addition of suitable nitrogen-containing neutral ligands, such as phenanthroline, ethylenediamine, and pyridine, to $\mathrm{Ag}(\mathrm{I}) /$ persulfate reactions resulted in the acceleration in the oxidation of $\mathrm{Ag}(\mathrm{I})$ to $\mathrm{Ag}(\mathrm{II}){ }^{9}$ This activating effect was attributed to a lowering of the $\mathrm{Ag}(\mathrm{II}) / \mathrm{Ag}(\mathrm{I})$ couple.

To investigate the possible interaction between 1 and $\mathrm{AgNO}_{3},{ }^{1} \mathrm{H}$ NMR studies were carried out in $\mathrm{D}_{2} \mathrm{O}$ to mimic reaction conditions (Figure 3). Downfield shifts of aromatic protons were observed upon addition of TFA (Figure 3b) or $\mathrm{AgNO}_{3}$ (Figure 3d) to 1 in $\mathrm{D}_{2} \mathrm{O}$. Upon addition of TFA and $\mathrm{AgNO}_{3}$ to $\mathbf{1}$ (Figure 3c), a slight upfield shift of aromatic protons is observed compared to the mixture of $\mathbf{1}$ and TFA (Figure $3 b$ ).

The lack of overlay of the spectra is consistent with equilibrium complexation between 1 and $\mathrm{Ag}(\mathrm{I})$ under reaction conditions. 
With some insight into the possible role of $\mathbf{1}$ we next focused on the mechanistic role of $\mathbf{2}$. An inverse rate order is typically indicative of two possible scenarios: 1) The presence of the reaction component shifts an equilibrium, decreasing the concentration of the intermediate prior to a rate determining step, or 2) the component behaves as an antagonist acting outside the desired pathway that leads to product. Given the long history of the $\mathrm{Ag}(\mathrm{I}) /$ persulfate oxidation system, it is instructive to examine the literature carefully for possible precedent to explain the unusual observations obtained from the kinetic studies. Studies on the interaction between $\mathrm{AgNO}_{3}$ and boronic acids in ammoniacal solution dates back to the 1880s. ${ }^{11}$ These early investigations showed that while alkyl boronic acids reduce $\mathrm{Ag}(\mathrm{I})$ through an intermediate Ag-alkyl, aromatic boronic acids form an insoluble salt. Heating of this salt led to hydrolytic cleavage producing an arene, boric acid and $\mathrm{Ag}_{2} \mathrm{O} .{ }^{11}$

To examine the $\mathrm{Ag}(\mathrm{I})$-initiated hydrolysis under reaction conditions, stoichiometric quantities of 2 and $\mathrm{AgNO}_{3}$ were stirred in 1:1 DCM: $\mathrm{H}_{2} \mathrm{O}$ solution. After approximately five minutes, the formation of a gray/silver colored precipitate was observed consistent with silver oxide described in previous studies. The formation of toluene as a by-product of this reaction was confirmed by gas chromatography-mass spectrometry (GC-MS). To further probe the system, two reactions were carried out. The first involved reacting $1.5 \mathrm{mmol}$ of 2 with $1.0 \mathrm{mmol} \mathrm{AgNO}_{3}$ in 1:1 DCM: $\mathrm{H}_{2} \mathrm{O}$ solution. A second reaction was run under the same conditions with $3.0 \mathrm{mmol}$ of $\mathbf{1}$. Approximately $0.84 \mathrm{mmol}$ of toluene formed when 1 was included in the reaction mixture, compared to $0.23 \mathrm{mmol}$ of toluene formed when $\mathbf{1}$ was excluded, a finding consistent with inhibition of $\mathrm{AgNO}_{3}$ and consumption of $\mathbf{2}$ outside of the desired reaction pathway. The increase in toluene formation in the presence of $\mathbf{1}$ is also consistent with interaction between 1 and $\mathrm{AgNO}_{3}$ and the classic studies on the reaction of $\mathrm{AgNO}_{3}$ and boronic acids in ammoniacal solutions. ${ }^{8,11}$

Based on the observed kinetic and spectroscopic data, the proposed reaction mechanism involves: i) a pre-equilibrium step in which $\mathbf{1}$ and $\mathrm{Ag}(\mathrm{I})$ form a complex, ii) the reduction of $\mathrm{S}_{2} \mathrm{O}_{8}{ }^{2-}$ by the $\mathrm{Ag}(\mathrm{I})-\mathbf{1}$ complex, which is the rate-determining step, and iii) an off-cycle step involving protodeboronation of $\mathbf{2}$ accelerated by the $\mathrm{Ag}(\mathrm{I})-\mathbf{1}$ complex (Scheme 2).

Assuming steady state approximation for the $\mathrm{Ag}(\mathrm{I})-\mathbf{1}$ complex, and accounting for all the states of $\mathrm{Ag}(\mathrm{I})$, the rate of reaction can be expressed as eq 2 (for full derivation refer to Supporting Information).

$$
-\frac{d[\mathbf{1}]}{d t}=k_{1} k_{2}[\mathbf{1}]\left[S_{2} O_{8}{ }^{2-}\right]\left[\mathrm{Ag}^{I}\right]_{t o t}\left(\frac{k_{-1}+k_{2}\left[S_{2} O_{8}{ }^{2-}\right]+k_{3}[\mathbf{2}]}{k_{-1}{ }^{2}+2 k_{-1} k_{3}[\mathbf{2}]+k_{3}{ }^{2}[\mathbf{2}]^{2}}\right)
$$

The derived rate law can be compared to the empirical rate law (eq 3), in which $\mathbf{1}, \mathrm{S}_{2} \mathrm{O}_{8}{ }^{2-}$, and $\mathrm{Ag}(\mathrm{I})$ are first order and $\mathbf{2}$ is inverse half order. The reaction orders in the empirical rate law can be equated to the first order of $\mathbf{1}$ and $\mathrm{Ag}(\mathrm{I})$, positive additive order of $\mathrm{S}_{2} \mathrm{O}_{8}{ }^{2-}$, and overall inverse fractional order of $\mathbf{2}$, as shown in the derived rate law.

$$
-\frac{d[\mathbf{1}]}{d t} \approx k_{\text {obs }} \frac{[\mathbf{1}]\left[\mathrm{S}_{2} \mathrm{O}_{8}^{2-}\right]\left[\mathrm{Ag}^{I}\right]_{t o t}}{[\mathbf{2}]^{0.5}}
$$

Aside from providing insight into the reaction mechanism, these results provide a means to optimize reaction conditions and increase the yield of the reaction. The inverse half order of 2 indicates that increasing its concentration is deleterious to reaction progress. Furthermore, addition of a reagent capable of preventing formation of catalytically inactive $\operatorname{Ag}(\mathrm{I})$ to its active form should be beneficial to reaction progress (See Supporting Information). To test 
this supposition, a reaction was initiated using $0.5 \mathrm{M} \mathrm{HNO}_{3}$ to prevent the formation of catalytically inactive $\mathrm{Ag}(\mathrm{I}) .{ }^{11 \mathrm{c}}$ Employing these modified conditions enabled the reduction of catalyst and oxidant loading to $10 \mathrm{~mol} \% \mathrm{AgNO}_{3}$ and 2 equiv of persulfate, respectively in a 1:1 solution of DCM and water under Ar atmosphere overnight, leading to an isolated yield of $90 \%$. Additionally, toluene side-product formation was reduced to $9 \%$ (with respect to 2 ).

Equipped with a rate expression for the system, the question that still remains unanswered is: which species is oxidizing the boronic acid, the $\mathrm{Ag}(\mathrm{II})$ or $\mathrm{SO}_{4}{ }^{-}$? The classic work of Kochi and others has shown that metastable $\mathrm{Ag}(\mathrm{II})$ is responsible for decarboxylation of carboxylic acids to produce radicals by $\mathrm{Ag}(\mathrm{I}) /$ persulfate. $^{12}$ This work was applied by Minisci and coworkers, in which the alkyl radical, generated from decarboxylation of an acid adds to a heteroarene to form substituted heterocycles. ${ }^{5}$ In the present reaction, Baran proposed that persulfate radical anion addition to the aryl boronic acid was responsible for intermediate aryl radical formation. ${ }^{4}$

To test the question posed above, we first examined the use of potassium 4-methylphenyl trifluoroborate (4) in place of $\mathbf{2}$. The reaction was performed under the unoptimized conditions shown in Scheme 1 and provided a $60 \%$ isolated yield of $\mathbf{3}$. Aryl trifluoroborates are known to hydrolyze under basic conditions. ${ }^{13}$ The stability of $\mathbf{4}$ under reaction conditions was examined in aqueous acidic media by monitoring the ${ }^{11} \mathrm{~B}$ NMR spectrum as described by Lloyd-Jones. ${ }^{13}$ No hydrolysis of $\mathbf{4}$ to $\mathbf{2}$ was observed. Next, the reaction with 2 was carried out in the presence of allyl acetate, a well-known radical trap for $\mathrm{SO}_{4}^{-.14}$ If $\mathrm{SO}_{4}{ }^{-}$is acting as the oxidizing agent in the reaction, the addition of allyl acetate would be deleterious to reaction progress. Interestingly, addition of 6 equiv of allyl acetate had no impact on yield and the rate of reaction increased slightly. This observation suggests that by decreasing the concentration of $\mathrm{SO}_{4}{ }^{-}$through capture by allyl acetate, the reaction is being driven forward toward the formation of product, presumably through the reduction of $\mathrm{S}_{2} \mathrm{O}_{8}{ }^{2-}$ by $\mathrm{Ag}(\mathrm{I})$ producing $\mathrm{Ag}(\mathrm{II})$. These additional experiments show that $\mathbf{4}$ is not hydrolyzed (i.e. remains quaternized) under reaction conditions, and reactions with 2 proceed even when $\mathrm{SO}_{4}{ }^{-}$is sequestered by allyl acetate. As a consequence, these experiments are consistent with a process where the oxidation proceeds through a $\mathrm{Ag}(\mathrm{II})$ mediated process. Since quaternized boron is more susceptible to single electron oxidation, ${ }^{15}$ we propose that water (solvent) or pyridine interacts with the aryl boronic acid to facilitate oxidation by $\mathrm{Ag}(\mathrm{II})$. A proposed mechanism for the reaction is shown in Scheme 3.

Under the conditions of the reaction, pyridine coordinates to $\operatorname{Ag}(\mathrm{I})$, followed by persulfate oxidation in the rate-limiting step. The resulting Ag(II)-pyridine complex oxidizes the arylboronic acid, producing an aryl radical, which can then add to the pyridinium ion leading to product. An off-cycle step is also involved outside of the desired pathway, in which the arylboronic acid is protodeboronated, leading to unwanted side products.

The mechanistic experiments described herein show an un-expected degree of complexity in the $\mathrm{Ag}(\mathrm{I}) /$ persulfate-catalyzed cross-coupling of arylboronic acids and pyridines, information that could not otherwise be extracted from the use of simple empirical models or studies based on product distributions. The mechanism derived from spectroscopic and kinetic studies shows that $\operatorname{Ag}(\mathrm{I})$ is activated for reduction of persulfate and an off-cycle protodeboronation by pyridine. These results provide the key mechanistic insight that enables control of the off-cycle process thus providing higher efficiency and yield. In addition, literature precedent and evidence provided herein demonstrate that $\mathrm{Ag}(\mathrm{II})$ is the likely oxidant responsible for formation of aryl radicals from aryl boronic acids. While the studies presented clarify several mechanistic details of the $\mathrm{Ag}(\mathrm{I}) /$ persulfate catalyzed cross- 
coupling of arylboronic acids and pyridines, the results may have impact in the design and refinement of other radical-based additions proceeding through catalytic oxidations mediated by $\mathrm{Ag}(\mathrm{I}) /$ persulfate.

\section{Supplementary Material}

Refer to Web version on PubMed Central for supplementary material.

\section{Acknowledgments}

R.A.F. is grateful to the National Institutes of Health (GM075960-03) for support of this work. We thank Dr. James Devery and Dr. Lawrence Courtney for useful discussion and aid in the elucidation of the reaction mechanism, and Dr. Brian Casey for initial work on this project

\section{References}

1. (a) Jahn U. Top Curr Chem. 2012; 320:121-452. [PubMed: 22025066] (b) Kozlowski MC, Morgan BJ, Linton EC. Chem Soc Rev. 2009; 38:3193-3207. [PubMed: 19847351]

2. (a) Narayanam JMR, Stephenson CRJ. Chem Soc Rev. 2011; 40:102. [PubMed: 20532341] (b) Tucker JW, Stephenson CRJ. J Org Chem. 2012; 77:1617. [PubMed: 22283525]

3. (a) John A, Nicholas KM. J Org Chem. 2011; 76:4158-4162. [PubMed: 21401207] (b) Chen X, Hao X, Goodhue CE, Yu J. J Am Chem Soc. 2006:6790-6791. [PubMed: 16719450] (c) Zhang C, Jiao N. J Am Chem Soc. 2010; 132:28-29. [PubMed: 20000433] (d) Fujiwara Y, Domingo V, Seiple IB, Gianatassio R, Del Bel M. J Am Chem Soc. 2011; 133:3292-3295. [PubMed: 21341741]

4. Seiple IB, Su S, Rodriguez RA, Gianatassio R, Fujiwara Y, Sobel AL, Baran PS. J Am Chem Soc. 2010; 132:13194-13196. [PubMed: 20812741]

5. Minisci F, Bernardi R, Galli R, Perchinummo M. Tetrahedron. 1971; 27:3575-3579.

6. Minisci F, Vismara E, Fontana F, Morini G, Serravalle M. J Org Chem. 1986; 51:4411-4416.

7. (a) Mathew JS, Klussman M, Iwamura H, Valera F, Futran A, Emanuelsson EAC, Blackmond DG. J Org Chem. 2006; 71:4711-4722. [PubMed: 16776495] (b) Blackmond DG. Angew Chem Int Ed. 2005; 44:4302-4320.(c) Devery JJ III, Conrad JC, MacMillan DWC, Flowers RA II. Angew Chem Int Ed. 2010; 49:6106-6110.(d) Choquette KA, Sadasivam DV, Flowers RA II. J Am Chem Soc. 2011; 133:10655-10661. [PubMed: 21619012]

8. (a) Bruehlman RJ, Verhoek FH. J Am Chem Soc. 1948; 70:1401-1404.(b) Bjerrum J. Acta Chem Scand. 1972; 26:2734-2742.(c) Vosburgh WC, Cogswell SA. J Am Chem Soc. 1943; 65:24122413.

9. (a) Alexiev A, Bontchev PR. Mikrochim Acta. 1970:13-19.(b) Bonchev PR, Aleksiev AA. Theor Exp Chem. 1975; 9:144-147.

10. Apelblat A, Korin E, Manzurola E. J Chem Thermodynamics. 2001; 33:61-69.

11. (a) Michaelis, Becker. Chem Ber. 1882; 15:181.(b) Johnson JR, Van Campen MG, Grummitt O. J Am Chem Soc. 1938; 60:111-115.(c) Seaman W, Johnson JR. J Am Chem Soc. 1931; 53:711723.

12. (a) Anderson JM, Kochi JK. J Am Chem Soc. 1970; 92:1651-1659.(b) Anderson JM, Kochi JK. J Org Chem. 1970; 35:986-989.

13. Butters M, Harvey JN, Jover J, Lennox AJJ, Lloyd-Jones GC, Murray PM. Angew Chem Int Ed. 2010; 49:5156-5160.

14. Kalb AJ, Allen TL. J Am Chem Soc. 1964; 86:5107-5112.

15. Shundrin LA, Bardin VV, Frohn HJ. Z Anorg Allg Chem. 2004; 630:1253-1257. 


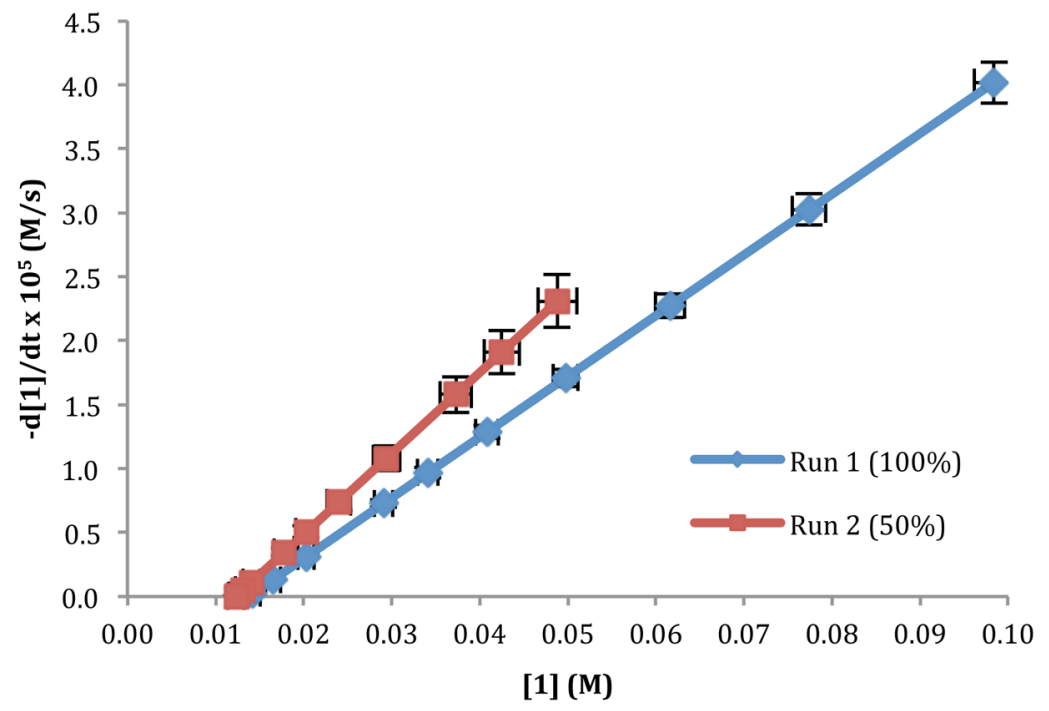

Figure 1.

Rate vs. [1] for same excess experiments. 


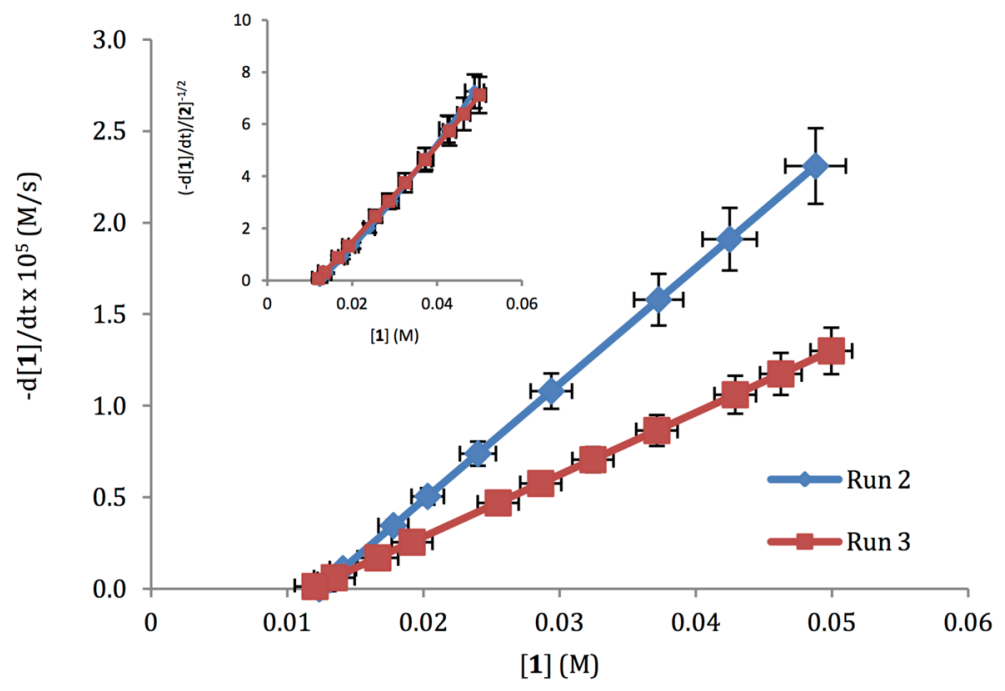

Figure 2.

Rate vs. [1] for different excess experiments for 2. Run 3 was performed by increasing [2] to $0.30 \mathrm{M}$ and keeping concentrations of all other reactants the same as in Run 2 . 
a)

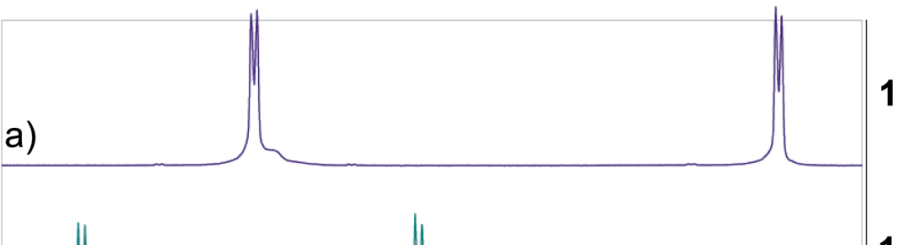

b)

c)

d)

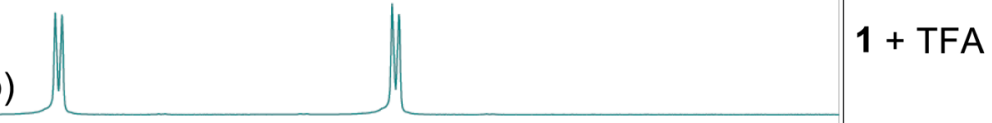

$1+\mathrm{TFA}+\mathrm{AgNO}_{3}$

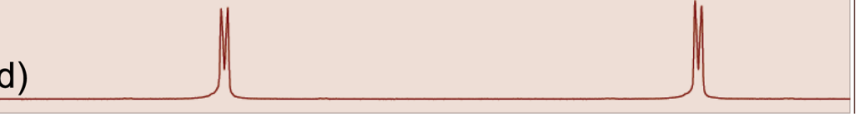

$1+\mathrm{AgNO}_{3}$

Figure 3.

${ }^{1} \mathrm{H}$ NMR spectra of $\mathbf{1}$ with additives 


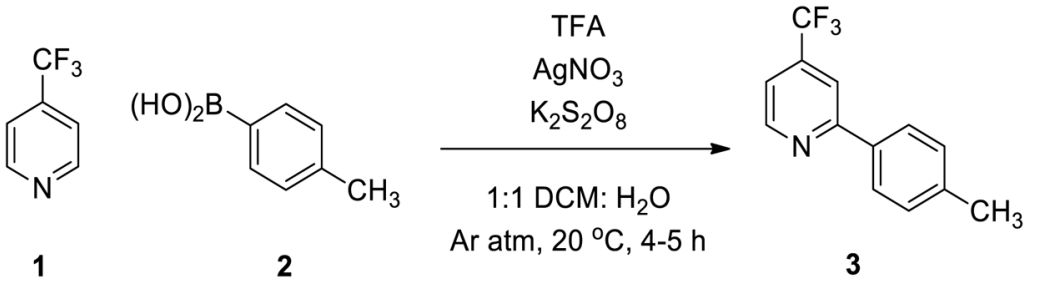

Scheme 1.

Cross-coupling reaction of electron- deficient pyridine with arylboronic acid 


$$
\begin{aligned}
1+\mathrm{Ag}^{+} & \frac{\mathrm{k}_{1}}{\mathrm{k}_{-1}} 1-\mathrm{Ag}^{+} \\
1-\mathrm{Ag}^{+}+\mathrm{S}_{2} \mathrm{O}_{8}{ }^{2-} & \stackrel{\mathrm{k}_{2}}{\mathrm{rds}} 1-\mathrm{Ag}^{2+}+\mathrm{SO}_{4}{ }^{2-}+\mathrm{SO}_{4}{ }^{-} \\
2+1-\mathrm{Ag}^{+} & \stackrel{\mathrm{k}_{3}}{\underset{\text { off cycle step }}{\longrightarrow}} \text { Toluene + Boric acid }+\mathrm{Ag}_{2} \mathrm{O}
\end{aligned}
$$

Scheme 2.

Mechanism of $\operatorname{Ag}(\mathrm{I}) /$ Persulfate-Catalysis in Coupling of Arylboronic acid and Electrondeficient Pyridine 


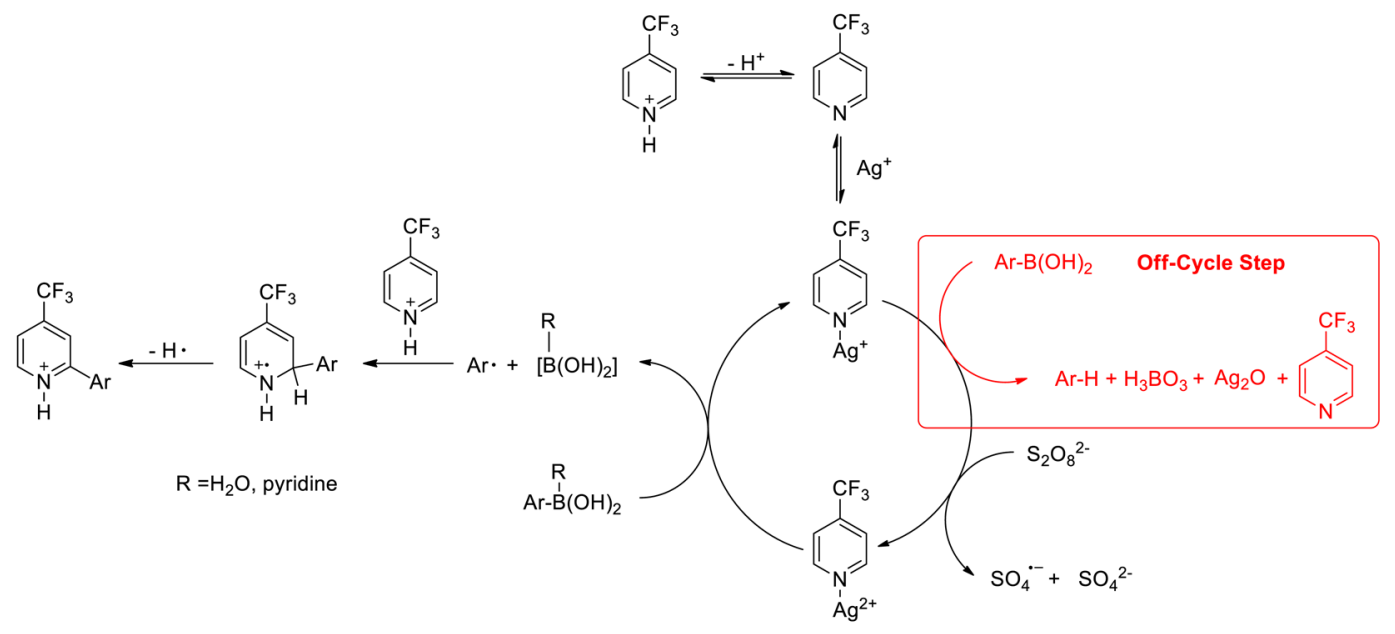

Scheme 3.

Proposed Mechanism of the Ag(I)/Persulfate-Catalyzed Arylation of Electron-deficient Pyridine 


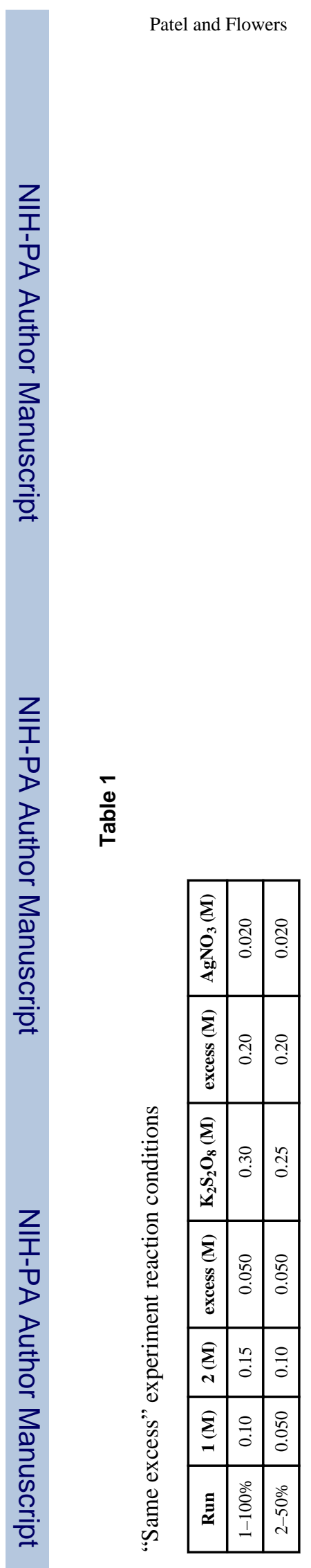

Page 12

J Am Chem Soc. Author manuscript; available in PMC 2014 March 27. 


\section{Table 2}

Observed Rate Orders of Substrates in Cross-Coupling Reaction of 1 and 2

\begin{tabular}{|c|c|c|c|}
\hline $\mathbf{1}$ & $\mathbf{2}$ & $\mathbf{K}_{\mathbf{2}} \mathbf{S}_{\mathbf{2}} \mathbf{O}_{\mathbf{8}}$ & $\mathbf{A g N O}_{\mathbf{3}}$ \\
\hline 1 & -0.5 & $0^{*}$ & 1 \\
\hline
\end{tabular}

Due to low solubility of $\mathrm{K}_{2} \mathrm{~S}_{2} \mathrm{O} 8\left(4.72 \mathrm{~g} / 100 \mathrm{ml}\right.$ at $\left.20{ }^{\circ} \mathrm{C}\right){ }^{10}$; when using $\mathrm{Na}_{2} \mathrm{~S}_{2} \mathrm{O} 8(54.6 \mathrm{~g} / 100 \mathrm{~mL})$, rate order shown to be approximately 1 . 